\title{
Direitos e deveres dos usuários do Sistema Único de Saúde: relato de experiência*
} Rights and duties of the Unified Health System users: experience report Derechos y deberes de los usuarios del Sistema Único de Salud: relato de experiencia

Recebido: $14 / 02 / 2018$
Aprovado: $25 / 10 / 2018$
Publicado: $29 / 01 / 2019$

\author{
Bruna Carolina Sousa Castro ${ }^{1}$ \\ Letícia Gabriela de Almeida ${ }^{2}$ \\ Rafaela Costa Silva ${ }^{3}$ \\ Bethania Ferreira Goulart ${ }^{4}$
}

Este artigo tem como objetivo relatar a experiência do grupo Programa de Educação Tutorial de Enfermagem na realização do projeto de extensão universitária “Direitos e Deveres dos Usuários do SUS". A atividade ocorreu entre outubro e dezembro de 2016, nos setores de clínica cirúrgica e ortopedia de um hospital de ensino, com participação de 10 alunos e 6 docentes do curso de graduação em enfermagem. Utilizou-se do conhecimento desenvolvido na perspectiva dialógica para abordagem da Carta dos Direitos dos Usuários da Saúde. O projeto buscou contribuir para o empoderamento dos pacientes sobre seus direitos e deveres enquanto usuários do SUS, para que os mesmos disponham de autonomia para reivindicá-los. Quando direitos e deveres dos usuários do SUS são articulados e estão fortalecidos nos serviços de saúde, isto pode conduzir à maior qualidade, equidade e resolutividade, proporcionando uma assistência mais digna, justa e equânime.

Descritores: Participação social; Educação em saúde; Conhecimento; Sistema Único de Saúde.

This article aims to report the experience of the group Programa de Educação Tutorial (Program of Tutorial Education) regarding the university extension project "Rights and Duties of the SUS users". Said project took place from October to December 2016, in the general surgery and orthopedics wards of a teaching hospital. Ten students and six professors of the nursing graduation course participated. The study used the knowledge developed from a dialogic perspective in the approach of the Charter of Health Users Rigths. The project aimed at contributing to empower the patients regarding their rights and duties as SUS users, so that they have autonomy to demand for them. When rights and duties of SUS users are articulated and strong in the health services, this can lead to an increased quality, equity, and a greater capacity to deal with problems, generating a more dignified, just, and equal assistance.

Descriptors: Social participation; Health education; Knowledge; Unified Health System

Este artículo tiene como objetivo relatar la experiencia del grupo Programa de Educación Tutorial de Enfermería en la realización del proyecto de extensión universitaria "Derechos y Deberes de los Usuarios del SUS". La actividad ocurrió entre octubre a diciembre de 2016, en los sectores de clínica quirúrgica y ortopedia de un hospital de enseñanza, con participación de 10 alumnos y 6 docentes de la carrera de graduación en enfermería. Se utilizó el conocimiento desenvuelto en la perspectiva dialógica para abordaje de la Carta de los Derechos de los Usuarios de la Salud. El proyecto buscó contribuir para el empoderamiento de los pacientes sobre sus derechos y deberes como usuarios del SUS para que los mismos dispongan autonomía para reivindicarlos. Cuando derechos y deberes de los usuarios del SUS son articulados y están fortalecidos en los servicios de salud, esto puede conducir a una mayor calidad, equidad y resolutividad, proporcionando asistencia más digna, justa y ecuánime.

Descriptores: Participación social; Educación en Salud; Conocimiento; Sistema Único de Salud.

1. Acadêmica de Enfermagem. Membro do Programa de Educação Tutorial - PET Enfermagem. Universidade Federal do Triângulo Mineiro (UFTM). Uberaba, MG, Brasil. ORCID: 0000-0003-0449-7061 E-mail: sousabrunac@gmail.com

2. Acadêmica de Enfermagem. Egressa do PET Enfermagem - UFTM. Uberaba, MG, Brasil. ORCID: 0000-0003-2156-6938 E-mail: almeida-lg@hotmail.com

3. Acadêmica de Enfermagem. Membro do PET Enfermagem - UFTM. Uberaba, MG, Brasil. ORCID: 0000-0003-0851-1908 E-mail: rafaela_etilco@yahoo.com.br

4. Enfermeira. Doutora. Professora Adjunta. Departamento de Enfermagem em Educação e Saúde Comunitária, UFTM, Uberaba, MG, Brasil. ORCID: 0000-0003-2855-6767 E-mail: bethaniagoulart@yahoo.com.br

Fonte de Financiamento: Secretaria de Educação Superior do Ministério da Educação/SESU-MEC. 


\section{INTRODUÇÃO}

A Constituição Federal de 1988 destaca um conceito ampliado de saúde e o princípio da universalidade, o qual aborda a saúde como direito de todos os indivíduos, cabendo ao Estado o dever de assegurar esse direito, reduzindo o risco de adoecimento e acometimento por outros agravos.

Por intermédio das lutas pela democracia, surgiu o Sistema Único de Saúde (SUS) constituído pelos princípios da universalidade, que garantem a atenção à saúde a todas as pessoas sem distinção; da equidade, segundo o qual todos os cidadãos são iguais perante o SUS, mas possuem particularidades, e da integralidade, que pressupõe uma assistência integral respeitando os direitos de cada cidadão ${ }^{1}$. Nesse sentido, o acesso aos serviços de saúde deve ser prestado de forma pública e integral à população $0^{2,3}$.

Para concretizar a proposta do SUS, foi desenvolvida a Carta dos Direitos dos Usuários do SUS, que tem como base seis princípios, a saber: todo cidadão tem direito ao acesso ordenado e organizado aos sistemas de saúde; ao tratamento efetivo e adequado de acordo com seu problema; ao atendimento mais humanizado, que o protege de discriminação, e ao atendimento respeitoso. Destaca ainda que compete ao cidadão a corresponsabilidade para que o atendimento seja efetuado de forma adequada; e aos gestores, cabe a defesa para que todos os princípios sejam efetivamente cumpridos 4 .

Apesar de sua instituição ter ocorrido há mais de 20 anos, ainda existem desafios a serem superados, em especial aqueles que tangem a mobilização social para defesa da saúde universal de qualidade.

Acredita-se que a frágil mobilização social decorre do pouco conhecimento da população quanto a seus direitos e deveres no contexto do SUS. A escassez desse conhecimento pelos usuários pode se revelar como fruto da carência de ações educativas. Mesmo que os profissionais possuam domínio sobre o assunto $^{5}$, isso não é suficiente para disparar uma sensibilização na comunidade. Isto pois, há pouco conhecimento a respeito da temática por parte da população, e não há meios e habilidades para reivindicar6.

Frente a isso é necessário compartilhar direitos e deveres dos usuários por meio de outro direito fundamental, que é a informação, geralmente mediada por profissionais de saúde ${ }^{7}$. Nesse sentido, a intencionalidade de ações educativas deve se pautar no desenvolvimento da corresponsabilidade dos usuários, tornandoos capazes de encarar dificuldades encontradas 5 .

A sociedade é pouco instrumentalizada no que diz respeito a informações sobre seus direitos e deveres, o que pode conduzir à passividade em torno da situação de saúde, conduzindo à tímida ou inexistente participação social ${ }^{6}$.

Há necessidade do empoderamento da população quanto a direitos e deveres dos usuários, na perspectiva do SUS, para possibilitar o conhecimento do contexto, habilidades e atitude para reivindicação dos mesmos. O empoderamento é resultante de um processo educativo, que oferece subsídios para desenvolvimento da autonomia e criticidade frente as políticas de saúde ${ }^{8}$. Isso pode contribuir para usuários mais conscientes e críticos quanto ao papel que podem e devem exercer como protagonistas na própria vida e nas escolhas em saúde.

A troca de informações sobre direitos e deveres dos usuários pode ser responsabilidade da equipe de saúde. Neste caso, os enfermeiros podem ser pontes para essa aproximação entre usuários e seus direitos e deveres, uma vez que a educação em saúde faz parte de sua formação profissional, tornando-os um dos principais agentes nesta mobilização, que visa ao cuidado integral do usuário9.

As ações comunicacionais, dialógicas e educativas sobre direitos e deveres dos usuários do SUS precisam abranger os indivíduos nos diversos níveis de atenção à saúde, proporcionando segurança aos usuários, fortalecendo assim sua participação nos serviços, colaborando com mudanças necessárias no cenário de saúde ${ }^{10}$. 
Considerando os níveis assistenciais, quando se remete ao nível terciário e a serviços hospitalares, constata-se que a percepção do usuário hospitalizado a respeito dos direitos e deveres está permeada pelo desconhecimento, e muitos apresentam medo de represálias dos profissionais que os assistem ${ }^{11}$. Nesse contexto, torna-se imprescindível a articulação da equipe de saúde, em especial o enfermeiro, para o compartilhamento de informações e reconstrução de valores e práticas organizacionais, para garantia e difusão dos direitos e deveres, tendo em vista a qualidade assistencial e sobretudo a segurança do paciente ${ }^{12}$.

Em virtude disso, percebe-se que o direito à saúde de qualidade contempla um sentido amplo, não restrito às áreas do campo da saúde, envolvendo administração pública e jurídica ${ }^{13}$. Evidencia-se a escassez de publicações abordando os direitos e deveres dos usuários do SUS. Entretanto, é oportuno ressaltar que a referida temática se apresenta como dispositivo crucial para a efetivação da participação social e democratização no espaço de saúde ${ }^{11}$.

0 presente estudo tem como objetivo relatar a experiência do grupo Programa de Educação Tutorial Enfermagem na realização do projeto de extensão universitária "Direitos e Deveres dos Usuários do SUS".

\section{MÉTODO}

Trata-se de relato de experiência de atividade extensionista vivenciada junto ao Programa de Educação Tutorial (PET) de Enfermagem, intitulada "Direitos e Deveres dos usuários do SUS", que ocorreu entre os meses de outubro e dezembro de 2016, no Hospital de Clínicas (HC) da Universidade Federal do Triângulo Mineiro (UFTM).

Contou com participação de 10 alunos divididos em duplas, ficando cada dupla responsável por um dia da semana, apenas em dias úteis, com horários variados, supervisionados por seis docentes do curso de graduação em Enfermagem da UFTM. Ao final de cada dia, a dupla elaborava um relatório da atividade, que compunha o diário de campo, base de consulta para esse relato.

A extensão universitária "Direitos e Deveres dos Usuários do SUS", com número de registro 315/2016 no SIGPROJ, foi realizada nos setores de ortopedia e clínica cirúrgica do HC-UFTM, contando com 17 e 61 leitos, respectivamente. 0 HC presta assistência de alta complexidade a 27 municípios que compõem a Região Ampliada de Saúde (RAS) Triângulo Sul.

Para dar início às atividades da extensão universitária, os acadêmicos passaram por uma capacitação fundamentada na Carta dos Direitos dos Usuários da Saúde, do Ministério da Saúde ${ }^{4}$, adquirindo conhecimentos sobre a temática. A capacitação, com duração de aproximadamente duas horas, foi conduzida por uma aluna, com apoio dos professores responsáveis pela atividade.

0 referencial metodológico orientador deste relato ancora-se no arcabouço do Empoderamento na Saúde. A palavra Empowerment já existente na Língua Inglesa, e significa "dar poder" a alguém para realizar uma tarefa sem precisar da permissão de outras pessoas. Para os contextos sociais, o conceito de Empoderamento - em especial aquele orientado por Paulo Freire - segue uma lógica ampliada da terminologia inglesa ${ }^{4,14}$.

Concebe-se que a pessoa, grupo ou instituição empoderada é aquela que realiza por si mesma, as mudanças necessárias e ações que a levam a evoluir e se fortalecer. Neste sentido, empoderamento pode ser um processo social, cultural, psicológico ou político por meio do qual indivíduos ou grupos sociais são capazes de expressar suas necessidades e preocupações, e conceber estratégias na tomada de decisões ${ }^{14}$.

De forma geral, são quatro componentes fundamentais ao processo de Empoderamento do paciente: a) compreensão de seu papel; b) aquisição de conhecimento suficiente para se engajar nos cuidados de sua saúde; c) habilidades e a facilitação da convivência no contexto que experimentam ${ }^{14}$, e d) autonomia (Figura 1). 


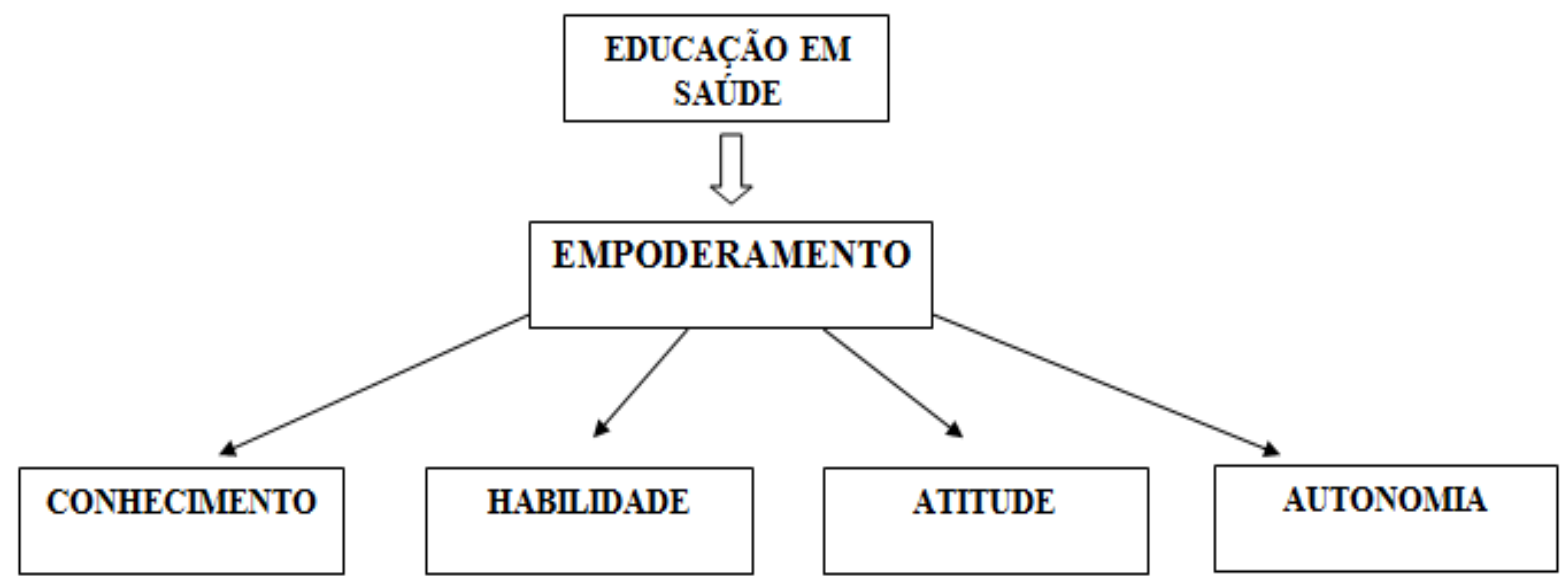

Figura 1. Mapa conceitual sobre educação em saúde e empoderamento.

Adaptado de Cesarino e Sciarra ${ }^{14}$.

\section{RESULTADOS}

Temas relacionados aos princípios apresentados na Carta dos Direitos dos Usuários da Saúde, orientações quanto às formas de abordagem do usuário e seu familiar, vestimenta e postura adequadas dos acadêmicos extensionistas e orientações gerais foram discutidos na capacitação.

Após esse momento, houve separação dos acadêmicos em duplas para cada dia da semana, seguindo suas disponibilidades de horário, sendo que cada dupla tinha a supervisão de, no mínimo, um professor responsável para acompanhar a atividade.

A partir do conhecimento prévio dos acadêmicos e das vivências dos usuários, houve uma troca de saberes, com intuito de os usuários adquirirem habilidades para tomar decisões, atitudes para construção de uma postura crítica e autoconhecimento para desenvolver autonomia.

Em decorrência disso, o usuário pode atuar como multiplicador de conhecimentos, compartilhando as informações no contexto social no qual está inserido. Essa experiência possibilita também, ao acadêmico, estar sensível às demandas e necessidades reais dos usuários dos serviços de saúde.

Ao todo, foram desenvolvidos 45 encontros, com duração de aproximadamente uma hora cada um, ocorrendo entre os meses de outubro e dezembro de 2016. As ações alcançaram diretamente 102 pacientes, dos quais 52 eram do sexo feminino $(50,9 \%)$ e 50 do sexo masculino (49,1\%), e 38 acompanhantes, sendo 34 do sexo feminino $(89,4 \%)$ e quatro do sexo masculino $(10,6 \%)$, totalizando 140 pessoas, 86 do sexo feminino $(61,4 \%)$ e 54 do sexo masculino $(38,6 \%)$.

A experiência possibilitou aos acadêmicos uma reflexão a respeito das situações de fragilidade e instabilidade emocional dos usuários, algo que nem sempre estão sendo preparados para enfrentar durante a graduação, e há situações em que a comunicação é elemento primordial para aprender a ouvir e a compreender o outro durante o processo de hospitalização.

Os relatórios elaborados continham as informações referentes ao desenvolvimento da ação naquele dia, como: data, setor, quantidade de usuários/familiares abordados, questionamentos, envolvimento dos usuários, esclarecimento de dúvidas e trocas de informações, comentários da população-alvo e a percepção dos acadêmicos quanto à atividade realizada.

Todos esses relatórios deram origem a um diário de campo, com vistas a centralizar as informações obtidas, para que as mesmas servissem de parâmetro para moldar a abordagem dos próximos encontros.

Durante as atividades, foram esclarecidos os princípios contidos na Carta, e um princípio muito lembrado pelos usuários/acompanhantes foi o primeiro, que diz respeito ao atendimento com ordem e organização, ou seja, é fundamental que o atendimento siga ordem de prioridade/necessidade. 
Foram relatadas, pelos usuários e acompanhantes, situações vivenciadas que corroboram com o cumprimento desse princípio, e apesar de estarem aguardando por atendimento também, não se importaram com pessoas que chegaram depois e foram atendidas primeiro em outros serviços de saúde, por compreenderem que necessitavam de atendimento prioritário.

Em relação à comunicação com a equipe de saúde, os usuários/acompanhantes verbalizaram que existe certa dificuldade, que se refere ao pouco conhecimento ou informações insuficientes quanto a seu quadro de saúde ou até mesmo sobre o tratamento. Isso vai em direção oposta ao segundo princípio da Carta, que afirma que todos têm direito a um atendimento de qualidade. Isto gera uma ansiedade $\mathrm{e}$ inquietação, além da revolta de muitos usuários com o atendimento.

Quanto ao direito de uma assistência humanizada e sem discriminação, referente ao terceiro princípio, a percepção sobre a satisfação com a assistência, pelos usuários e acompanhantes, revela que os profissionais do local do estudo além de serem preparados para os procedimentos que realizavam, ainda apresentavam características humanizadas, como o acolhimento, a escuta ativa e a empatia, características que não foram observadas em outros serviços de saúde.

Outro aspecto que se destacou diz respeito ao quarto princípio, que assegura que todos precisam ter seus direitos como usuários respeitados. Por meio da experiência vivenciada nesse projeto de extensão universitária, constatou-se, com base nos relatos dos usuários/acompanhantes, que na prática o caminho que se segue é o oposto. Diante disso, identificou-se que a solicitação do prontuário médico pelos usuários $\mathrm{e}$ acompanhantes para leitura não é realizada, e há certo receio do usuário quanto à recusa de se submeter a algum procedimento ou exame.

O serviço de Ouvidoria do HC-UFTM foi bastante discutido durante os encontros da atividade, como um dos espaços de escuta e também para que fossem realizadas sugestões, críticas e elogios, baseados nas experiências vivenciadas durante a internação. Com essa informação, os usuários/acompanhantes revelaram que há desconhecimento do serviço de Ouvidoria como um espaço também para elogios à assistência, acreditando que era voltado apenas para críticas e sugestões.

No que diz respeito aos deveres dos usuários do SUS, que constituem o quinto princípio, a experiência possibilitou ao acadêmico compreender que há algumas situações de omissão ou distorção, por parte do usuário, de alguma informação referente à saúde para a equipe, e isso dificulta a assistência, podendo gerar prejuízo à saúde dele.

O sexto e último princípio refere-se ao cumprimento da mencionada Carta dos direitos dos usuários da saúde por todos, e talvez seja o princípio mais difícil de ser vivenciado no cotidiano da experiência, visto que engloba todos os princípios apresentados anteriormente. Ele também confere a responsabilidade pelo respeito desses direitos ao governo em seus diferentes níveis - federal, estadual e municipal. Entretanto, evidenciou-se que o usuário ou acompanhante procuram algum desses órgãos para terem acesso aos serviços de saúde, principalmente para viabilização de algum procedimento cirúrgico.

0 projeto de extensão universitária, foco do presente relato, buscou contribuir para o empoderamento dos usuários do SUS, devido à percepção durante os encontros realizados, pois havia escassez de conhecimento a respeito dos direitos $\mathrm{e}$ deveres enquanto usuários dos serviços de saúde.

Constatou-se também interesse por parte dos usuários e acompanhantes na temática, os quais expressaram que as ações possuíam relevância para promover a autonomia dos usuários para serem mais ativos no tocante às políticas de saúde.

\section{DISCUSSÃO}

A experiência apresentou-se como um conjunto de iniciativas potenciais para conciliar a informação em saúde no sentido 
de ampliar a autonomia das pessoas no processo decisório de condutas de saúde, além de evidenciar que o desconhecimento, o desrespeito e a ilegitimidade do poder de escolha, por parte dos pacientes, podem favorecer processos de cuidado desumanizados.

Nesse sentido, a Carta dos direitos e deveres dos usuários do SUS propõe que profissionais de saúde mantenham uma relação mais ampla com as pessoas assistidas, compreendendo suas necessidades para além das necessidades físicas ${ }^{2,3}$.

A integração do grupo de graduandos do PET Enfermagem nesse cenário contribuiu para que as abordagens realizadas durante o processo de internação do paciente não se limitassem ao tema adoecimento. Isso possibilitou que nesse momento, frente ao quadro geral de cada pessoa internada, houvesse uma sensibilização sobre o SUS, visto ser ele o recurso crucial para a promoção, prevenção, cuidado e reabilitação das pessoas em âmbito nacional2,3,15.

A sobrecarga de atividades dificulta que o enfermeiro da unidade de internação empreenda ações, no seu cotidiano de trabalho, como as relatadas nessa vivência ${ }^{15}$. Deste ponto, o trabalho realizado pelos graduandos do PET Enfermagem demonstrou ser capaz de realizar ações de educação em saúde de maneira a potencializar o autocuidado e a autonomia do indivíduo.

Ademais, a experiência relatada contempla uma iniciativa de mediação da informação para empoderamento das pessoas assistidas na unidade hospitalar, instrumentalizando-as para que possam questionar e reivindicar, e por conseguinte propor melhorias e adequações ao cuidado recebido.

O empoderamento do indivíduo, por meio da informação, é crucial para a autotransformação das pessoas, principalmente quando desloca o usuário do SUS da categoria de receptor passivo de informação para ser participativo ${ }^{7,16}$, atuando como protagonista e corresponsável no plano terapêutico.
Aqueles que se propõem a assistir o ser humano, antes de tudo precisam assumir uma postura de respeito e compromisso. Nas unidades de internação hospitalar, tradicionalmente há centralidade na abordagem da doença. Portanto, a experiência relatada aqui se apresentou como possibilidade inovadora para articular aspectos humanísticos e do direito à saúde em uma intervenção junto a esse cenário específico7,15,16. Isso significa que atuar no setor saúde requer não somente competência técnica, mas também humana.

Quanto às limitações do estudo, a experiência relatada nesse momento não teve a pretensão de medir a satisfação dos usuários participantes. Entretanto, como se trata de uma vivência singular em que se coadunam dimensões do cuidado humanizado, do empoderamento em saúde, e da informação sobre o SUS, em um cenário tradicionalmente voltado para repetição de práticas centralizadas na doença, torna-se potencial a sua reprodução em contextos similares.

\section{CONCLUSÃO}

0 presente estudo mostrou o quanto é imprescindível a humanização na assistência à saúde. Nessa perspectiva, elucida-se a necessidade de proporcionar empoderamento a pacientes no que diz respeito a seus direitos e deveres enquanto usuários do SUS, para que os mesmos disponham de autonomia para reivindicar seus direitos.

A vivência no referido projeto de extensão permitiu identificar que, quando direitos e deveres dos usuários do SUS são articulados e estão fortalecidos nos serviços de saúde, isto pode conduzir à maior qualidade, equidade e resolutividade, proporcionando assistência mais digna, justa e equânime.

A experiência revela a importância do conhecimento desenvolvido na perspectiva dialógica. Foi possível compreender que a disseminação e troca de saberes colaboram com as práticas de emancipação do usuário. A compreensão dessa temática contribui para que o usuário possa fazer suas próprias 
escolhas, por meio de uma metodologia de educação transformadora que promova autonomia para fornecer meios, a fim de disparar mudanças nos serviços de saúde.

\section{REFERÊNCIAS}

1. Silva Junior GB, Dias ER. Avaliação da satisfação dos usuários de um serviço de saúde público-privado no nordeste do Brasil e a judicialização da saúde. Rev Direito Sanit. [Internet]. 2016 [citado em 15 set 2017]; 17(2):13-29. Disponível em: http://www.journals.usp.br/rdisan/article /view/122303

2. Calegari RC, Massarollo MCKB, Santos MJ. Humanização da assistência à saúde na percepção de enfermeiros e médicos de um hospital privado. Rev Esc Enferm USP. [Internet]. 2015 [citado em $20 \mathrm{dez} 2017$ ]; 49(Esp2):42-7. Disponível em: http://www.scielo.br/scielo.php?script=sci_a rttext\&pid=S0080-

62342015000800042\&lng=en

3. Onias JMTC, Carvalho JÁ, Escobar KAA. Humanização e integralidade da atenção à saúde reprodutiva da mulher no Sistema Único de Saúde - SUS. Rev Cient ITPAC. [Internet]. 2013 [citado em 15 set 2017]; 6(1). Disponível em: https://assets.itpac.br/arquivos/Revista/61 /2.pdf

4. Ministério da Saúde (Br). Carta dos direitos dos usuários da saúde. 2ed. Brasília, DF: Ministério da Saúde; 2007.

5. Fonseca GS, Paulino TSC, Morais IF, Valença CN, Germano RM. Percepção de usuários e profissionais de saúde sobre o sistema único de saúde no município de Santa Cruz-RN. Rev Bras Promoç Saúde [Internet]. 2012 [citado em 15 set 2017]; 25(4):455-61. Disponível em: http://periodicos.unifor.br/RBPS/article/vie $\mathrm{w} / 2548$

6. Macêdo HJR, Macêdo AFF, Souza MNA. Conhecimentos de alunos da educação de jovens e adultos sobre seus direitos enquanto usuários do SUS. Ciênc Desenv Rev Eletrônica FAINOR [Internet]. 2014 [citado em 15 set 2017]; 7(1):199-210. Disponível em: http://srv02.fainor.com.br/revista/index.ph $\mathrm{p} / \mathrm{memorias} /$ article/view/279/184
7. Leite RAF, Brito ES, Silva LMC, Palha PF, Ventura CAA. Acesso à informação em saúde e cuidado integral: percepção de usuários de um serviço público. Interface (Botucatu) [Internet]. 2014 [citado em 15 set 2017]; 18(51):661-72. Disponível em: http://www.scielo.br/scielo.php?script=sci_a rttext\&pid=S1414-

$32832014000400661 \& \operatorname{lng}=\mathrm{en}$.

DOI:

http://dx.doi.org/10.1590/1807-

57622013.0653

8. Taddeo PS, Gomes KWL, Caprara A, Gomes AMA, Oliveira GC, Moreira TMM. Acesso, prática educativa e empoderamento de pacientes com doenças crônicas. Ciênc Saúde Colet. [Internet]. 2012 [citado em 15 set 2017]; 17(11):2923-30. Disponível em: http://www.scielo.br/scielo.php?script=sci_a rttext\&pid=S1413-

81232012001100009\&lng=en

9. Oliveira FLB, Gomes DPS, Almeida Junior JJ. A extensão universitária no acolhimento e vista aberta em um hospital público em Santa Cruz/RN. Ext Soc. [Internet]. 2013[citado em 15 set 2017]; 1(6). Disponível em: https://periodicos.ufrn.br/extensaoesocieda de/article/view/4294/3503

10. Gomes AMA, Sampaio JJC, Carvalho MGB, Nations MK, Alves MSCF. Código dos direitos e deveres da pessoa hospitalizada no SUS: o cotidiano hospitalar na roda de conversa. Interface (Botucatu) [Internet]. 2008 [citado em 15 set 2017]; 12(27):773-82. Disponível em:

http://www.scielo.br/scielo.php?script=sci_a rttext\&pid=S1414-

32832008000400008\&lng $=\mathrm{en}$

11. Rocha FLR, Marziale MHP, Carvalho MC, Cardeal ISF, Campos MCT. A cultura organizacional de um hospital público brasileiro. Rev Esc Enferm USP. [Internet]. 2014 [citado em 15 set 2017]; 48(2):308-14. Disponível em: http://www.scielo.br/pdf/reeusp/v48n2/pt 0080-6234-reeusp-48-02-308.pdf

12. Borges GS, Fonseca AF. A judicialização das políticas públicas de saúde. Rev Espaç Acad. [Internet]. 2017 [citado em 23 set 2017]; 16(189):75-86. Disponível em: http://periodicos.uem.br/ojs/index.php/Esp acoAcademico/article/view/32195. 
13. Silva CCL, Santos LMC, Gomes CO. Saúde \& Transformação Social. [Internet]. 2016 [citado em 15 set 2017]; 6(2):132-8. Disponível em:

http://incubadora.periodicos.ufsc.br/index.p hp/saudeetransformacao/article/view/2923 /4478

14. Cesarino CB, Sciarra AMP. Empoderamento na saúde. Arq Ciênc Saúde [Internet]. 2017 [citado em 23 nov 2017]; 24(3):1-2. Disponível em: http://www.cienciasdasaude.famerp.br/inde x.php/racs/article/view/928/719

15. Backes DS, Souza MHT, Marchiori MTC, Colomé JS, Backes MTS, Lunardi Filho WD. O Sistema Único de Saúde idealizado versus o realizado: contribuições da Enfermagem. Rev Latinoam Enferm. [Internet]. 2014 [citado em $20 \mathrm{dez} 2017$ ]; 22(6):1026-33. Disponível em: http://www.scielo.br/pdf/rlae/v22n6/pt_ 0104-1169-rlae-22-06-01026.pdf

16. Villas-Bôas ME. O direito-dever de sigilo na proteção ao paciente. Rev Bioét. [Internet]. 2015 [citado em 15 set 2017]; 23(3):513-23. Disponível em: http://www.scielo.br/scielo.php?script=sc i_arttext\&pid=S198380422015000300513\&lng=en DOI: http://dx.doi.org/10.1590/1983-

80422015233088

\section{CONTRIBUICÕES}

Bruna Carolina Sousa Castro, Letícia Gabriela de Almeida, Rafaela Costa Silva participaram da concepção, busca bibliográfica, redação e revisão crítica. Bethânia Ferreira Goulart auxiliou na redação e na revisão crítica.

\footnotetext{
Como citar este artigo (Vancouver)

Castro BCS, Almeida LG, Silva RC, Goulart BF. Direitos e deveres dos usuários do Sistema Único de Saúde: relato de experiência. REFACS [Internet]. 2019 [citado em inserir dia, mês e ano de acesso]; 7(1):109-116. Disponível em: inserir link de acesso. DOI: inserir link do DOI.

Como citar este artigo (ABNT)

CASTRO, B. C. S. et al. Direitos e deveres dos usuários do Sistema Único de Saúde: relato de experiência. REFACS, Uberaba, MG, v. 7, n. 1, p. 109-116, 2019. Disponível em: <inserir link de acesso>. Acesso em: inserir dia, mês e ano de acesso. DOI: inserir link do DOI.

Como citar este artigo (APA)

Castro, B.C.S.; Almeida, L.G., Silva, R.C. \& Goulart, B.F. (2019). Direitos e deveres dos usuários do Sistema Único de Saúde: relato de experiência. REFACS, 7(1), 109-116. Recuperado em: inserir dia, mês e ano de acesso de inserir link de acesso. DOI: inserir link do DOI.
} 